\title{
LEUCOTOMY FOR PAIN
}

\section{BY \\ ALICK ELITHORN, ERIC GLITHERO, and ELIOT SLATER}

\begin{abstract}
From the Department of Psychological Medicine and the Neurological Research Unit (Medical Research Council), the National Hospital for Nervous Diseases, Queen Square, London
\end{abstract}

Leucotomy is advised for a patient whose main complaint is pain generally as a last resort and not because careful consideration shows that this is the treatment of choice. There is general agreement that the operation should not be performed if there are grounds for thinking that some other treatment will provide effective relief, but many clinicians only advise leucotomy when all other possible procedures have been tried and have failed. McKissock (1953) has stigmatized this as bad practice and few will disagree with his view that what in a final analysis proves the most beneficial operation should be the initial one. This can only be so if it is possible to select those patients with complaints of severe pain, for whom leucotomy is the best treatment, balancing probability of benefit against risk of harm.

The patient who suffers from pain for any considerable length of time has to contend not only with the pain itself, but also with a variety of psychological effects secondary to the pain such as anxiety, introspection, distressful rumination, and depression. His disability is complex, and this may explain why the views of different authorities vary so widely as to the significance of these psychiatric factors. Thus Freeman and Watts (1950) say that " generalized pain and distress can be alleviated more readily than pain and distress due to direct involvement of nerve trunks ". This view is also supported, amongst others, by Grantham (1950), Smolik (1950), and one of the major French schools (Petit-Dutaillis, Messimy, and Berges, 1953). In sharp opposition, other authorities report that better results are obtained where the psychological reaction is minimal (Scarff, 1950; King, Clausen, and Scarff, 1950). Dynes and Poppen (1949) also claim that patients with metastatic malignant disease with good pre-operative personalities responded best. Similarly Le Beau and Gaches (1949) found their best results in patients with an organic basis for their pain and no abnormal mental state. Le Beau has modified this opinion; he elaborates a concept of "souffrance", a state of painful mental anguish, which he regards as the main indication for psychosurgery (Le Beau, Choppy, Gaches, and Rosier, 1954).
These different views may not reflect incompatible observations. What is generally missing is an analysis in formal psychiatric terms of the character of the complaint of pain, and the relation of this analysis to the final outcome. Thus there is general agreement that while leucotomy does not alter the patient's ability to perceive pain it does alter the psychological components of the pain situation. A logical consequence of such a premise is that the aim of the operation is to produce a change in personality. It is generally hoped that this change will be solely beneficial, in that the patient will become less sensitive to his pain without being any less sensitive to his social environment. Indeed many authorities appear to believe that leucotomy can produce relief of intractable organic pain without significant personality deterioration. This belief is usually based on experience with a modified operation. There are, it is true, several reports of the successful use of standard bilateral leucotomy for pain without loss of social adjustment, but it seems clear that in every case the adjustment has been in the face of personality deficits of the frontal lobe type.

\section{Modified Operations}

There are three ways in which a modified operation on the frontal lobes might relieve pain.

In the first place, there might be a selective interference with the perception of " autonomic" or visceral pain. Workers at Yale (Hamlin, Delgado, Chapman, and Rosvold, 1953) have claimed that it is possible to relieve intractable visceral pain by producing small focal electrolytic lesions in the ventromedial part of the frontal lobes. However, it has never been shown that after orbital damage there is abolition or reduction of the perception of experimentally induced visceral pain.

Secondly, a small focal lesion might cause a specific inattention or dysgnosia for the painful aspects of a stimulus, which would, nevertheless, be perceived. This phenomenon, often described clinically, has been called asymbolia for pain (Schilder and Stengel, 1931). 
The third way in which a modified operation might help would be by causing a generalized impairment of the ability to form appropriate emotional responses. In such a case the desired lack of distress on receipt of the distressing painful stimulus would be but a part of a wide range of incapacities which could be classified as deterioration of personality. Cobb and his colleagues at Harvard (Bonner, Cobb, Sweet, and White, 1953) studied a series of 38 patients who had undergone a variety of operations: bilateral standard leucotomy, bilateral lower quadrant frontal leucotomy, unilateral frontal leucotomy on the dominant side and unilateral excision of the orbital cortex. Their results indicated that the degree to which pain is relieved is closely paralleled by the extent of deterioration of personality, and they concluded that such operations could be justified " only in very special circumstances". There are many other authorities, e.g., PetitDutaillis et al., (1953) who believe that some impairment of personality is a price that has to be paid before an operation on the frontal lobes will relieve pain or the distress it causes.

\section{Material and Methods}

The present study is based on the results obtained with 25 patients who underwent leucotomy-type operations for the relief of intractable pain. These patients form part of a larger series treated by leucotomy. Many others in this series complained of various pains, but in the 25 cases reported here pain was the initial complaint and the patient was referred for consideration of leucotomy in the belief that it was pain which determined his disability. All patients had previously been extensively investigated medically and neurologically and in nearly all cases an adequate presumptive physical cause for the complaint of pain had been demonstrated. No attempts were made to reproduce patients' pain experimentally. A separate study on the effect of leucotomy on the individual's tolerance and reactivity to pain has already been reported (Elithorn, Piercy, and Crosskey, 1955).

The clinical difficulty of assessing the severity and intractability of a physically painful lesion has recently been discussed by Botterell, Callaghan, and Jousse, (1954) and by Turnbull (1954). The latter has pointed out that not only was there a small proportion of terminal cases of carcinoma of the cervix in which intractable pain was not reported, but also that the estimations of gynaecologists as to the incidence of intractable pain amongst their cases varied widely-from negligible to $100 \%$. The presence, therefore, of an organic lesion, known to be severely painful in some patients, does not prove that in any given case the patient suffers severe pain due to organic nerve involvement.

In the present instance an estimate of the physical importance of the " organic" element in the pain situation was derived partly from the consistency and verisimilitude of the patient's account of his pain, partly from the signs of distress observed when the patient was not aware that he was under surveillance, and partly from the relatives' story as to the amount the pain interfered with the patient's activities when he was notas he was in consultation-directing his whole attention to a careful appreciation of his symptoms. A history of previous breakdowns in relation to psychological stresses was also admitted as evidence; the more easily the patient had become distressed in the past, the less severe would be the pain which one would assume to cause any particular degree of present disturbance. This estimate of the severity of the organic pain for the present 25 patients is given in Table I.

With four patients (classified ++++ ) there could be little doubt that the disabilities were severe and very painful. In nine other cases $(+++)$ marked organic pain was the central feature and presumptive cause of the illness. In seven cases $(++)$ organically determined pain had precipitated or determined a psychological reaction which was the major disability. In five cases $(+)$ the complaint of pain, even though based on organic pathology, was thought to be chiefly determined by the psychiatric condition.

After in-patient observation the available evidence was discussed at a conference attended by all members of the department. The operation was then recommended to the patient and relative in terms of the probability of worth-while relief. The final decision was left to the patient.

After the operation and a period of in-patient rehabilitation, the patient and his relatives were required to attend a special follow-up clinic. At this clinic a consistent drive was made to help the patient over every hurdle facing him, to get him to take up as normal a way of life as possible, and to get him back to work.

For the purpose of the present investigation each patient attended for a formal assessment. This interview took place on an average 23.6 months (range six to 58) after the operation. Most patients have been seen frequently since their attendance for this assessment, and the overall evaluations of the operations are derived from all the information available. The minimum follow-up period is thus 17 months, the longest 78 months, with an average of $40 \cdot 3$. The duration of the follow-up in individual cases is given in Table $I$.

At the formal assessment the patient was asked the following questions: Had the operation helped him; if so, which symptoms had improved? If not, had any symptoms improved? Which symptoms had not improved ? Had any bad effects been noticed ? Had there been any change in his personality ? What was his own rating of the operation, was he glad he had had it, did he regret it, or was he unable to say? A very similar list of questions was put to the relative, who was furthermore asked about social effects. Both patient and relative were then taken through a list of the complaints suffered before operation, and asked what change there had been in respect of each of them.

Whoever makes it, the evaluation of leucotomy as a treatment is in the final analysis a subjective one. The importance of giving due weight to the views of the patient and the relatives has recently been emphasized elsewhere (Elithorn and Slater, 1956). In the present series the 
authors agreed together that more than two-thirds of the patients had benefited from leucotomy. In sharp contrast two-thirds of the patients and relatives felt that the operation had not helped. This conflict of opinion appeared to reflect the fact that the patients and their relatives were concerned primarily about the failure of the operation to relieve the pain whereas the authors were more influenced by an overall appraisal which included such variables as an improvement in mood, a better social adjustment, and an apparent reduction in suffering.

In an attempt, therefore, to provide a more objective picture of the effect of the operation on the patient's behaviour a social behaviour rating scale was devised.

\section{SYMPTOMS}

\begin{tabular}{|c|c|}
\hline Score & Criteria \\
\hline & A. Patient's reaction \\
\hline $\begin{array}{l}5 \\
4\end{array}$ & $\begin{array}{l}\text { Symptom free; in excellent form } \\
\text { Occasionally mild symptoms-never complains sponta- } \\
\text { neously; no specific symptoms but not really well }\end{array}$ \\
\hline 3 & $\begin{array}{l}\text { Cccasional moderate or persistent slight symptoms; complains } \\
\text { rarely or only when asked }\end{array}$ \\
\hline 2 & $\begin{array}{l}\text { Severe symptoms occasionally; moderate persistent symptoms, } \\
\text { complains sometimes }\end{array}$ \\
\hline 1 & $\begin{array}{l}\text { Persistent, severe symptoms which can be borne; occasional } \\
\text { times of relative ease; complains frequently }\end{array}$ \\
\hline \multirow[t]{2}{*}{0} & Constantly complaining; state unendurable; suicidal risk \\
\hline & B. Social $r$ \\
\hline 5 & $\begin{array}{l}\text { No demands to be met by family or hospitals } \\
\text { Family life largely unhindered by patient's symptoms }\end{array}$ \\
\hline 3 & $\begin{array}{l}\text { Patient's symptoms occasionally disrupt family life; } \\
\text { occasional treatment provided }\end{array}$ \\
\hline 2 & $\begin{array}{l}\text { Symptoms and general condition often have to be considered } \\
\text { and allowances made by rest of family or friends; routine } \\
\text { treatment required }\end{array}$ \\
\hline 1 & $\begin{array}{l}\text { Family, friends, or hospitals receive frequent and heavy } \\
\text { demands; regular treatment necessary }\end{array}$ \\
\hline 0 & $\begin{array}{l}\text { Family life revolves around patient's illness; constant } \\
\text { attention. sympathy, or treatment given }\end{array}$ \\
\hline
\end{tabular}

\section{EMPLOYMENT}

\begin{tabular}{|c|c|}
\hline Score & Criteria \\
\hline & A. Amount \\
\hline 5 & $\begin{array}{l}\text { Full-time employment with changes only for the better; } \\
\text { independent; provides for others }\end{array}$ \\
\hline 4 & $\begin{array}{l}\text { Full-time employment with short periods off work; three- } \\
\text { quarter time steady; occasional changes in same type of } \\
\text { job; independent with some difficulty }\end{array}$ \\
\hline 3 & $\begin{array}{l}\text { Half-time regular employment; full-time with frequent } \\
\text { changes in same status job; largely independent; some } \\
\text { help needed to meet commitments }\end{array}$ \\
\hline 2 & $\begin{array}{l}\text { Half-time work; regular periods off; frequent changes to } \\
\text { poorer jobs; needing much economic help }\end{array}$ \\
\hline 1 & $\begin{array}{l}\text { Odd jobs of casual work; mainly dependent upon State. } \\
\text { social agencies, or relatives }\end{array}$ \\
\hline \multirow[t]{2}{*}{0} & Given up working altogether; parasitical \\
\hline & B. Performance \\
\hline 5 & Proficient: responsible; reliable; enterprising \\
\hline 4 & $\begin{array}{l}\text { Generally efficient and adequate; occasional help or support } \\
\text { needed; tidy; clean; uses thought and plans work }\end{array}$ \\
\hline 3 & $\begin{array}{l}\text { Adequate and neat, but support and allowances needed; } \\
\text { routine work requiring no responsibility }\end{array}$ \\
\hline 2 & $\begin{array}{l}\text { Poor, untidy, careless or erratic; supervision needed. but } \\
\text { can be relied upon to carry out instructions }\end{array}$ \\
\hline 1 & $\begin{array}{l}\text { Passenger; neglectful and dirty; retained out of sympathy; } \\
\text { constant support or supervision needed }\end{array}$ \\
\hline 0 & Liability: a responsibility or hindrance to others \\
\hline
\end{tabular}

Such a rating scale still depends on the subjective evaluation of quantitative data but does, nevertheless, permit a more detailed assessment of the efficacy of treatment. The patient's social behaviour was related to this scale for each year of his illness and of the post-operative follow-up period. The scales were as below:

\section{Results}

It should perhaps be emphasized that the results reported and discussed here are those found at follow-up not less than six months after the operation. Immediately after the operation, many patients showed much greater improvement than that now

\section{FAMILY RELATIONSHIPS}

\begin{tabular}{|c|c|}
\hline Score & Criteria \\
\hline & A. Responsibility \\
\hline 5 & $\begin{array}{l}\text { Takes a fully responsible role; takes other members' wishes } \\
\text { into account; budgets and manages affairs well }\end{array}$ \\
\hline 4 & $\begin{array}{l}\text { Responsible and manages well; some help and direction } \\
\text { from others needed; living within income }\end{array}$ \\
\hline 3 & $\begin{array}{l}\text { Accepts routine or habitual spheres of responsibility; takes } \\
\text { a responsible role only when pushed; living at income level }\end{array}$ \\
\hline 2 & $\begin{array}{l}\text { Displays very limited or habitual responsibility with en- } \\
\text { couragement; occasional display of responsibility when } \\
\text { absolutely necessary; lacking forethought; living slightly } \\
\text { beyond means }\end{array}$ \\
\hline $\begin{array}{l}1 \\
0\end{array}$ & $\begin{array}{l}\text { Completely dependent; no concept of value of money } \\
\text { Only self-concerned; scrounges }\end{array}$ \\
\hline & B. $A f f$ \\
\hline 5 & $\begin{array}{l}\text { Spontaneous feeling and concern for others; warmth of } \\
\text { personality ; dependable }\end{array}$ \\
\hline 4 & $\begin{array}{l}\text { Predominantly affable and dependable; spontaneously } \\
\text { friendly; occasionally helpful }\end{array}$ \\
\hline 3 & $\begin{array}{l}\text { Considerate and cooperative only when necessary; responsive } \\
\text { to affection though lacking in initiative }\end{array}$ \\
\hline $\begin{array}{l}2 \\
1 \\
0\end{array}$ & $\begin{array}{l}\text { Largely indifferent; sometimes querulous but amenable } \\
\text { Contentious; self-concerned } \\
\text { Negativistic; hostile; demanding of much attention }\end{array}$ \\
\hline & \\
\hline
\end{tabular}

\section{COMMUNITY RELATIONSHIPS}

\begin{tabular}{|c|c|}
\hline Score & Criteria \\
\hline & A. Social graces \\
\hline 5 & $\begin{array}{l}\text { Charming, pleasant, easily makes spontaneous personal } \\
\text { relationships; tactful; a good sense of interdependence }\end{array}$ \\
\hline 4 & $\begin{array}{l}\text { Friendly; affable; able to accommodate to others with ease; } \\
\text { a good sense of appropriate social behaviour }\end{array}$ \\
\hline 3 & $\begin{array}{l}\text { Cooperative and friendly only occasionally; polite, responds } \\
\text { to rather than initiates social intercourse }\end{array}$ \\
\hline 2 & $\begin{array}{l}\text { Some difficulty in forming social relationships but desires } \\
\text { them: can be pleasant at times but rather lacking in tact }\end{array}$ \\
\hline 1 & $\begin{array}{l}\text { Reluctant to engage in social intercourse; domineering or } \\
\text { imperious; ungracious; completely lacking in thought for } \\
\text { others; apathetic }\end{array}$ \\
\hline 0 & $\begin{array}{l}\text { Social manners repugnant or offensive to others; constantly } \\
\text { arousing displeasure }\end{array}$ \\
\hline & B. Leis \\
\hline 5 & $\begin{array}{l}\text { Spontaneous social or cultural interests; participates with } \\
\text { initiative; a good sense of social obligation; balanced and } \\
\text { versatile in approach to leisure activities }\end{array}$ \\
\hline 4 & $\begin{array}{l}\text { Interest and activity with some initiative; but of ten passive; } \\
\text { having some creative or cultural hobbies or a single } \\
\text { enthusiastic activity }\end{array}$ \\
\hline 3 & $\begin{array}{l}\text { Spasmodic or transient active interests; completely passive } \\
\text { but steady interests; sense of social responsibility only with } \\
\text { support }\end{array}$ \\
\hline 2 & $\begin{array}{l}\text { A very limited sphere of interests; only passive hobbies, } \\
\text { e.g.. cinema; a tendency to be concerned only with per- } \\
\text { sonal rights rather than social obligations }\end{array}$ \\
\hline 1 & $\begin{array}{l}\text { Asocial; no interests; tendency to lead the life of a social } \\
\text { hermit }\end{array}$ \\
\hline $\mathbf{0}$ & Anti-social trends \\
\hline
\end{tabular}


TABLE I

BASIC DATA

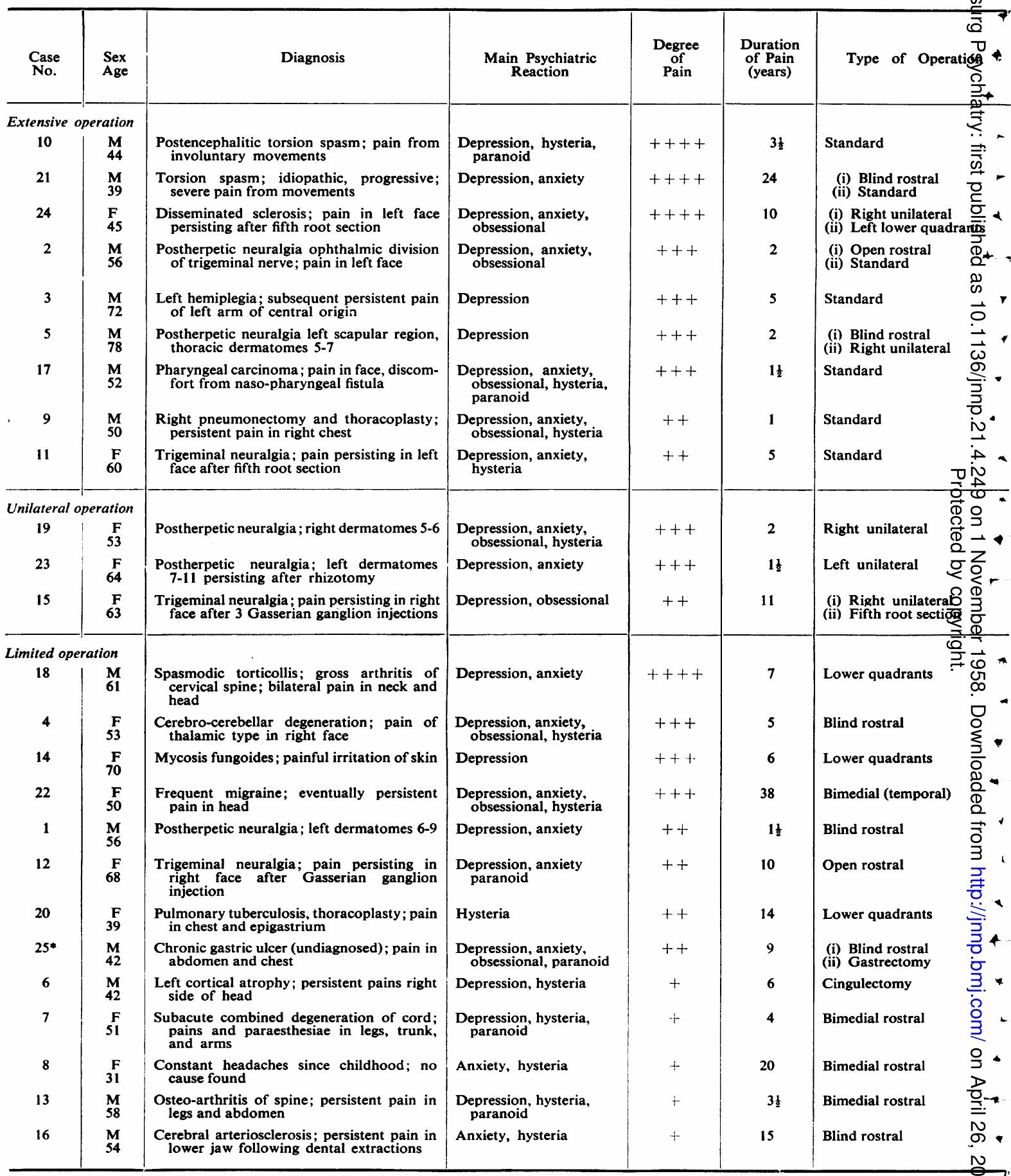

* This patient's pain, which persisted after leucotomy, was subsequently relieved by gastrectomy. Earlier and repeated investigations had failę to 
TABLE I-continued

BASIC DATA

\begin{tabular}{|c|c|c|c|c|c|c|c|}
\hline \multirow{2}{*}{$\begin{array}{c}\text { Duration of } \\
\text { Follow-up } \\
\text { (months) } \\
+\end{array}$} & \multirow[b]{2}{*}{ Effect on Pain } & \multirow{2}{*}{$\begin{array}{l}\text { Psychiatric } \\
\text { Reaction } \\
\text { Improved }\end{array}$} & \multicolumn{5}{|c|}{ Has Operation Helped? } \\
\hline & & & Patient & Relative & Physician & $\begin{array}{c}\text { Extent of Personality } \\
\text { Change }\end{array}$ & $\begin{array}{l}\text { Regain on Final } \\
\text { Follow-up Social } \\
\text { Ratings (\%) }\end{array}$ \\
\hline 52 & No change & Depression & No & No & Improved & Marked & +7 \\
\hline-20 (Died) & No change & Depression & - & - & Unimproved & Severe & -17 \\
\hline 18 & Less severe & Less distressed & Yes & No & Worse & Marked & -16 \\
\hline-29 & No change & $\begin{array}{l}\text { Depression, } \\
\text { anxiety, } \\
\text { obsessional }\end{array}$ & No & Yes & Much improved & Definite & +50 \\
\hline - 30 & Little change & Depression & No & Yes & Much improved & Marked & +59 \\
\hline 40 & No change & Depression & No & No & Much improved & Marked & +51 \\
\hline .22 (Died) & No change & $\begin{array}{l}\text { Depression, } \\
\text { anxiety, } \\
\text { hysteria }\end{array}$ & No & Yes & Improved & Definite & -8 \\
\hline 63 & Worse & Depression & Yes & Yes & Improved & Definite & +37 \\
\hline - 78 & No change & Depression & Yes & Yes & Improved & Severe & +69 \\
\hline 5 & & & & & & & \\
\hline - 64 & No change & Depression & No & No & Unimproved & Slight & +33 \\
\hline$\ldots 27$ (Died) & Worse & Less distressed & - & - & Worse & Definite & +28 \\
\hline 60 & No change & $\begin{array}{l}\text { Anxiety, } \\
\text { obsessions }\end{array}$ & Yes & Yes & Improved & Negligible & +42 \\
\hline - 36 & Worse & Depression & No & No & Unimproved & Definite & +17 \\
\hline - 53 (Died) & No change & Depression & Yes & - & Much improved & Negligible & +23 \\
\hline$\underbrace{34}$ & Less severe & Depression & No & - & Improved & Severe & +14 \\
\hline 22 & Worse & Less distressed & No & No & Worse & Slight & -36 \\
\hline 55 & Much better & $\begin{array}{c}\text { Depression, } \\
\text { anxiety }\end{array}$ & Yes & Yes & Much improved & Definite & +88 \\
\hline 46 & Improved & $\begin{array}{c}\text { Depression, } \\
\text { anxiety }\end{array}$ & Yes & No & Improved & Severe & +26 \\
\hline 31 & Much worse & Depression & No & No & Unimproved & Slight & +56 \\
\hline 40 & No change & $\begin{array}{c}\text { Anxiety, } \\
\text { obsessions }\end{array}$ & - & No & Worse & Definite & +27 \\
\hline 63 (Died) & Much better & Depression & Yes & Yes & Much improved & Slight & +88 \\
\hline$\perp \quad 28$ & Worse & Depression & No & No & Improved & Definite & +55 \\
\hline-23 & No change & $\begin{array}{c}\text { Depression, } \\
\text { anxiety }\end{array}$ & No & No & Improved & Slight & +147 \\
\hline-24 & No change & Depression & No & No & Improved & Slight & +70 \\
\hline - 54 (Died) & No change & $\begin{array}{c}\text { Depression } \\
\text { anxiety }\end{array}$ & No & No & Improved & Definite & -15 \\
\hline
\end{tabular}


TABLE II

MEAN SOCIAL RATINGS FOR WHOLE GROUP

\begin{tabular}{|c|c|c|c|c|}
\hline Rating Scales $(0-10)$ & $\begin{array}{l}\text { (a) } \\
\text { Premorbid }\end{array}$ & $\begin{array}{c}\text { (b) } \\
\text { Pre-operative }\end{array}$ & $\begin{array}{c}\quad(c) \\
\text { Final Follow-up }\end{array}$ & $\begin{array}{l}\frac{c-b}{a-b} \times 100 \\
\text { Regain of } \\
\text { Ground Lost }\end{array}$ \\
\hline $\begin{array}{l}\text { Symptoms ( } 10=\text { symptom-free }) \\
\text { Employment } \\
\text { Family relationships } \\
\text { Community relationships }\end{array}$ & $\begin{array}{l}8 \cdot 6 \\
8 \cdot 5 \\
7 \cdot 6 \\
5 \cdot 7\end{array}$ & $\begin{array}{l}0.9 \\
1.6 \\
1.9 \\
1.8\end{array}$ & $\begin{array}{l}4 \cdot 3 \\
3 \cdot 4 \\
3 \cdot 6 \\
3 \cdot 4\end{array}$ & $\begin{array}{l}45 \% \\
27 \% \\
29 \% \\
40 \%\end{array}$ \\
\hline Mean values (for all four scales) & $7 \cdot 6$ & $1 \cdot 6$ & 3.7 & $35 \%$ \\
\hline
\end{tabular}

recorded. Some reported total relief from pain. In the majority of cases, however, this returned within three months and by then became as bad as ever.

Table I presents the basic data for each patient. The results obtained with the rating scales are presented in Table II and discussed first. These are then related to the clinical assessments and the views of the patients and their relatives.

Fig. 1 shows an example of a rating profile. Such profiles were constructed for all 25 patients. For discussion here we have taken three corresponding points in each patient's history: The premorbid ratings, the immediately pre-operative ratings, and the final follow-up ratings. The mean values for these points are given in Table II. On the symptom scale the mean premorbid rating is 8.6 , with 12 patients being symptom-free and scoring 10; none scoring less than 6 . Pre-operatively the mean score falls to 0.9 ; at this level there is not only complete incapacity but life itself is almost unendurable. Only one patient scores as high as 3 and 11 score 0 . The mean score at the final follow-up is $4 \cdot 3$, indicating the persistence of a moderately severe degree of suffering. Seven patients gain 1 point or less; none gain more than 7 . The mean gain of 3.4 points following the operation, however, represents the regain of $45 \%$ of the ground lost from the premorbid

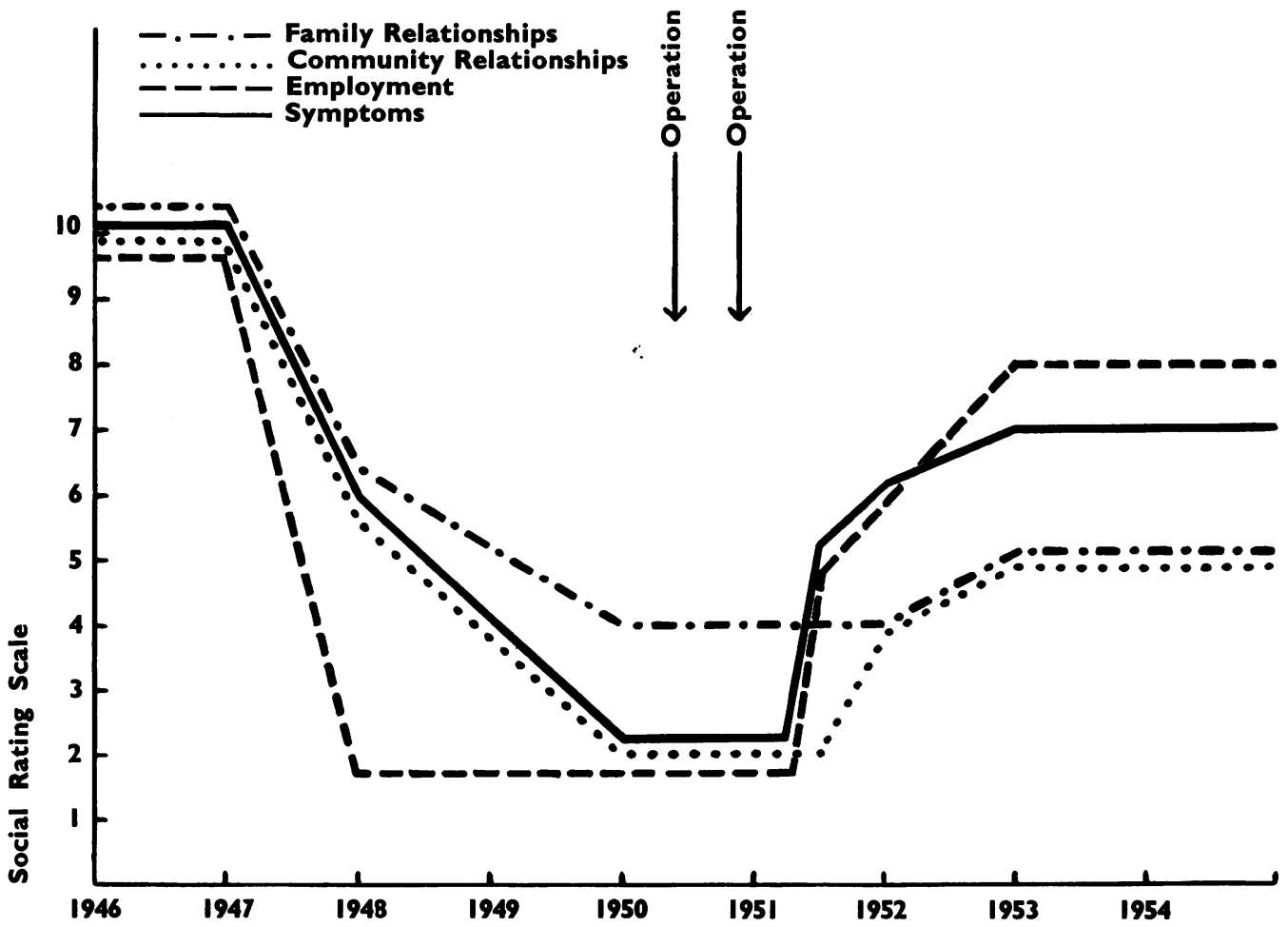

FIG. 1.-Social assessment rating profile (Case 2). 
mean of 8.6 . This degree of recovery is greater than that found in the other ratings.

The employment ratings show a similar picture. The premorbid ratings have a mean of $8 \cdot 5$. Before their illness 13 patients were in full effective employment and have ratings of 10 , and only three have ratings below 7 . Pre-operatively the mean rating has fallen to 1.6 , the majority of patients showing almost complete dependence in the home and out of it. Eleven patients score 0 , but it is noteworthy that even at this nadir in their lives three patients score 6 or 7 . These exceptional individuals, all women, continued to work effectively in their homes in spite of frequent and bitter complaints of severe pain. At the final follow-up the mean rating has risen to $3 \cdot 4$, representing a very marked degree of persisting disablement, and a regain of only $27 \%$ of the ground lost through illness. However, great variability is shown. Eight patients score 0, three of them having dropped to this point from a slightly higher pre-operative level. On the other hand, seven patients have final scores of 7,8 , or 9 , indicating a very satisfactory restitution of working powers. If, however, we look at the results obtained with three women who retained their capacity to work during their illness, we find that one had no relief of symptoms and still maintained her working capacity; another, with slight relief of symptoms, was almost back to full working capacity, while the third, with moderate symptomatic relief, became almost incapable of any work. The general correlation, in fact, is subject to noteworthy exceptions.

In the field of family relationships, we find a mean premorbid score of $7 \cdot 6$, seven patients scoring 10 , and five scoring 5 points or less. Pre-operatively the mean score drops to 1.9 , with eight zero scores and only two patients scoring as high as 6. At final follow-up the mean score has risen to $3 \cdot 6$, a regain of $29 \%$ of the ground lost by illness. The final score can hardly, however, be regarded as satisfactory.

In the field of community relations the ratings give, perhaps, a rather less depressing picture. The premorbid score is not high at $5 \cdot 7$, and one cannot say that our patients were as a group a very sociable lot of people. Premorbidly, the mean score falls to $1 \cdot 8$, rising again in final follow-up to $3 \cdot 4$, a regain of $40 \%$ of the ground lost.

Correlation coefficients which express the relationships between the changes in the different fields can be calculated. In the first place we may correlate the changes in scores which occur in the different fields between the pre-operative and follow-up ratings. These correlations are given in Table III. They are fairly high, and show that on the whole improvement or its reverse in any one field tends to go with similar changes in the other fields.
TABLE III

INTERCORRELATIONS BETWEEN FINAL FOLLOW-UP RATINGS

\begin{tabular}{lr|c|c|c|c}
\hline \multicolumn{2}{c|}{ Rating Scale } & S & E & FR & CR \\
\hline Symptoms & (S) & & & & \\
Employment & (E) & +0.55 & & \\
Family relationships (FR) & +0.60 & +0.82 & \\
Community relationships(CR) & +0.63 & +0.68 & +0.84 & \\
\hline
\end{tabular}

As these four types of rating are closely correlated and have much in common, it is justifiable to sum them to obtain a more widely based estimate of psychological normality and successful social adaptation. If this is done for each patient at each stage, i.e., premorbidly, pre-operatively, and finally, we may determine whether there is any correlation between the patient's ratings at each of these three times. If the three times of rating are numbered 1 to 3 , then we have: $r_{1,2}=+0 \cdot 26, r_{2,3}=+0 \cdot 34$, $r_{1,3}=+0 \cdot 27$. These positive correlations indicate that there is a "personal equation" affecting the degree of adjustment at each of the three stages, independently of the illness or its treatment, but that this not of a high order. This is what one would expect in the case of severe organic disorders subjected to an organic method of treatment.

\section{Clinical Assessments}

It is of interest to compare the assessments based on these ratings made independently by the psychiatric social worker and the holistic and impressionist views formed by the patient and the relative and in the clinic.

Twenty-three of the 25 patients survived to be asked six months or more after operation whether the leucotomy had helped them or not; 14 denied relief, one replied "yes and no", and only eight $(35 \%)$ answered affirmatively. Similarly of the 21 relatives who were asked whether the operation had helped the patient, only eight $(38 \%)$ thought that it had. In only five cases $(24 \%)$ did both patient and relative think the operation had helped. These replies compare very unfavourably with those obtained with other patients, leucotomized not for the relief of pain but for the treatment of primarily psychiatric illnesses. In this latter series $75 \%$ of 80 patients and $89 \%$ of 72 relatives thought that the operation had been of value to the patient.

Clinical assessment, based on interviews in the clinic and reports of behaviour at home and at work, indicated that the operation had been well worth while in over two-thirds of the cases: six were classified as " much improved ", 11 as " improved ", four as "unchanged", and four were regarded as being " worse". This discrepancy of views requires discussion. The social ratings strongly support the 
TABLE IV

MEAN SOCIAL RATINGS FOR OPERATIVE GROUPS

\begin{tabular}{|c|c|c|c|c|c|c|c|c|c|c|c|c|}
\hline & \multicolumn{4}{|c|}{ Premorbid } & \multicolumn{4}{|c|}{ Pre-operative } & \multicolumn{4}{|c|}{ Final Follow-up } \\
\hline & $\mathbf{E}$ & $\mathbf{S}$ & FR & CR & $\mathbf{E}$ & $\mathbf{S}$ & FR & CR & $\mathbf{E}$ & $\mathbf{S}$ & FR & $\mathbf{C R}$ \\
\hline $\begin{array}{l}\text { Extensive operation } \\
\text { Limited operation } \\
\text { Unilateral operation }\end{array}$ & $\begin{array}{l}8 \cdot 8 \\
8 \cdot 1 \\
9 \cdot 3\end{array}$ & $\begin{array}{l}9 \cdot 0 \\
8 \cdot 2 \\
8 \cdot 7\end{array}$ & $\begin{array}{l}8 \cdot 1 \\
6 \cdot 9 \\
8 \cdot 7\end{array}$ & $\begin{array}{l}6 \cdot 8 \\
5 \cdot 1 \\
5 \cdot 3\end{array}$ & $\begin{array}{l}1 \cdot 4 \\
1 \cdot 2 \\
3 \cdot 7\end{array}$ & $\begin{array}{l}0.6 \\
0 \cdot 8 \\
2 \cdot 3\end{array}$ & $\begin{array}{l}2 \cdot 2 \\
1 \cdot 2 \\
3 \cdot 7\end{array}$ & $\begin{array}{l}1 \cdot 6 \\
1 \cdot 7 \\
2 \cdot 7\end{array}$ & $\begin{array}{l}2 \cdot 9 \\
3 \cdot 4 \\
5 \cdot 3\end{array}$ & $\begin{array}{l}3 \cdot 9 \\
4 \cdot 5 \\
4 \cdot 7\end{array}$ & $\begin{array}{l}2 \cdot 6 \\
3 \cdot 8 \\
5 \cdot 0\end{array}$ & $\begin{array}{l}2 \cdot 8 \\
3 \cdot 8 \\
3 \cdot 0\end{array}$ \\
\hline
\end{tabular}

clinical assessment. If the total scores are considered 20 of the 25 patients $(80 \%)$ showed some increase in score, though in six cases this was five points or less.

Experimental work (Chapman, Rose, and Solomon, 1950; Elithorn et al., 1955) has shown that the perception of pain and the immediate responses to a painful stimulus are generally not reduced by leucotomy. It is therefore not surprising that patients whose main subjective complaint is unaffected by the operation should not regard it as a success. Of the 25 patients, 19 described their pains as unchanged or worse, only two described them as much better. Nearly the whole of the improvement observed clinically, therefore, was in the affective field, and this was reflected in an improved social adjustment. When faced with the observation that they were more effective people, the majority of patients did not deny this but claimed it was due to the successful outcome of their own determined struggle with a disability that had been essentially unaltered by leucotomy.

The Extent and Site of Operative Interference

Details of the various operative techniques employed are given in Table I. The techniques of the modified operations have been described elsewhere by the surgeons concerned (McKissock, 1953; Jackson, 1954). For the present analysis the operations have been divided into two classes: "limited" and "extensive". In the former the intention was to divide half or less of the white matter of the frontal lobes, in the latter more widespread damage was attempted: of these seven were full bilateral "standard" operations, two full unilateral operations with partial incisions on the contralateral side. Table IV shows the relationship between the extent of operation and the mean improvements on the pre-operative ratings. It must be remembered in comparing the results obtained with the two types of operation that such a comparison will show a bias against the extensive group, since this contains a few patients who first had a minor unsuccessful leucotomy and were subsequently operated on again. In the following analysis nine patients who had an "extensive" operation are compared with 13 who had a "limited" one. The three patients who had only a unilateral standard leucotomy have been omitted. In the extensive group three patients thought they had been helped, five thought not; in the second group the numbers are four against eight. In the first group the relatives thought the patient had been helped in five cases, not helped in three; in the second group the numbers are two and nine. Patients leucotomized for pain, therefore, show a very slight preference for an extensive operation. The relatives have a more marked and similar preference. The clinical assessment also attributes better results to the extensive operation: three out of nine are much improved in this group, and in the limited group only three out of 13 are so classified. Similarly, in the extensive group, two of the nine patients are classified as unimproved or worse, while in the limited group four out of 13 are so classified. These findings, though only suggestive, reflect the views of the patients and relatives in the larger series (Elithorn and Slater, 1956). Their main interest lies in the fact that they stand in sharp contrast to the observations made with the rating scales. Thus in the limited group there are four patients with 20 points of improvement or better; there are none in the extensive group. In the latter there are three patients who have minus scores, as against only two in the limited group. The mean improvement in the extensive group is 6.6 points, in the limited group 10.5 points. If we break down the limited group into small sub-groups, we find that the single patient submitted to cingulectomy gains 22 points. The four patients with bimedial opera-

GAIN ON FINAL FOLLOW-UP RATINGS FROM PRE-OPERATIVE RATINGS

\begin{tabular}{|c|c|c|c|c|}
\hline & $\mathbf{E}$ & $\mathbf{S}$ & FR & CR \\
\hline $\begin{array}{l}\text { Extensive operation } \\
\text { Limited operation } \\
\text { Unilateral operation }\end{array}$ & $\begin{array}{r}+1.5 \\
+2.2 \\
+1.6\end{array}$ & $\begin{array}{l}+3 \cdot 3 \\
+3 \cdot 7 \\
+2 \cdot 4\end{array}$ & $\begin{array}{l}+0.4 \\
+2.6 \\
+1.3\end{array}$ & $\begin{array}{l}+1 \cdot 2 \\
+2 \cdot 1 \\
+0.3\end{array}$ \\
\hline
\end{tabular}


tions average 11.5 points, the three patients with lower quadrant cuts average 9.7 points, and the five patients with rostral operations average 8.0 points.

This clear tendency for gains on the rating scales to be greater with the limited operations contrasts with the preference for the results obtained with the extensive operations shown by patient, relative, and clinician. They are all impressed in the first place by actual relief from suffering. Here extensive operations have a clear advantage and our observations support the findings of others who have emphasized that it is the quantity of frontal lobe damage which chiefly determines the degree of apathy towards pain. In the social assessment, more weight is given to differences in behaviour. The lives of many patients have improved, sometimes to a remarkable extent, yet the patients themselves and their relatives still believe that they have not been helped. In addition the social ratings place greater emphasis on the social effects of post-operative defects. Table IV shows the average number of points gained on each rating scale for the two groups.

\section{Severity of the Painful Lesion}

Careful study of these 25 cases shows that the more clearly it was established that the pain itself was severe the less effective was leucotomy as a treatment. Three of the four patients in the group with very severe pain $(++++)$ were classified clinically as unimproved or worse after the operation, and the mean improvement on the social score is $\mathbf{0 . 0}$. In the next group $(+++)$, three of the nine patients are unimproved or worse, and their mean improvement score is $\mathbf{6 . 8}$. In the next group $(++)$ of seven, one is not improved, and one is worse; the mean improvement is 11.7 points. In the last group $(+)$, in which the psychiatric element was thought to predominate, all improved clinically; the mean improvement is $14 \cdot 0$. This strongly supports the findings of those who believe that prefrontal leucotomy, even in an extensive form, is not an adequate method of treatment of severe organic pain.

\section{Effect of the Psychiatric Concomitants}

The work of Sargant, Partridge and Pippard, amongst many others, has established that in psychiatric cases some " psychopathological" processes respond better to leucotomy than do others. When the primary illness is an anxiety state, an obsessional disorder, or a non-cyclical depression, then the outlook with psychosurgery is far better than when it is schizophrenia, cyclical insanity, or a hysterical illness (Partridge, 1950; Sargant, 1953; Pippard, 1955, 1956). Preliminary analysis of the relationship between the degree of improvement and the psychological reaction shown by the present cases suggests that these findings do not necessarily apply to patients with intractable pain (see Table I). Thus it is not obvious that those in whom the psychiatric reaction was one of depression or anxiety have done better than those in whom the predominant attitude was thought to be an hysterical one. This difference in the present series reflects in part the overriding importance of the severity of the pain as the chief variable determining the outcome of any given operation. However, closer inspection of the material reveals that in these cases psychological mechanisms are affected in the same way as in purely psychiatric cases.

In 22 of the 25 cases depression was present. In 12 of them it was a marked symptom and in all but one (Case 7) it was reactive in type. Twenty patients with depression survived to be questioned; all but three reported some relief from this particular symptom. Four said that they were never depressed. However, this total abolition of depressive feelings was not confirmed by their relatives, who reported that although the symptoms of depression were less severe they did still occur. Characteristically, for all the patients there was a reduction in the duration of the periods of depression and frequently a decrease in the depth of the emotion experienced. Two patients, who before the operation had been consistently depressed, reported that subsequently this symptom was directly associated with attacks of pain (Cases 10 and 22). Clearly in these patients suffering pain, as in psychiatric patients generally, frontal lobe damage had greatly reduced the individual's ability to develop a depressive reastion. When such a reaction did develop it was relatively ill-sustained.

In 16 patients a tendency to anxiety was present. In all 16 cases operation produced a reduction in this tendency. In the case of the standard leucotomies this was often profound. The effect of this reduction on the total picture was, however, marked only in those four cases in which the anxiety was considered pre-operatively to have been excessive and of aetiological significance (Cases 1, 8, 12, and 25). Three of these four patients thought that the operation had helped them. The fourth, who showed marked hysterical features, not only said that the operation had not helped and that the pains were the same, but she also denied any reduction in her tendency to get tense and anxious. She did, however, admit to a decreased frequency of palpitations and to being much less worried by her specific fears of insanity and pregnancy. In fact, she was considerably better (Case 8).

In six of the present cases the disability was 
thought to depend largely on hysterical mechanisms (Cases 6, 8, 9, 13, 16, and 20); in seven other cases hysterical mechanisms were thought to play a secondary role in determining the character of the illness. In these 13 cases the results were classified as improved in 10 and as unimproved or worse in three. Of the 12 patients in whom hysterical mechanisms were absent or unimportant, five were unimproved or worse and only seven improved. This finding is at variance with the observation that hysterical illnesses respond poorly to leucotomy. There is probably no true discrepancy; the different findings may well reflect diagnostic difficulties. Where pain is clearly severe hysterical responses are overlooked: where the patient's complaints appear excessive the value judgment of "hysteria " is more often made. In these circumstances the importance of underlying depression, anxiety, or obsessional trends may be underestimated.

Only in one patient (Case 25) was it likely that obsessional features were of major importance: in nine others they played a definite role. Where their presence indicated excessive preoccupation with a relatively mild pain the outlook was correspondingly bright. If, however, obsessional traits complicated a painful state which was in other ways intractable (Cases 22 and 24) they appeared to exert a detrimental influence. All but one (Case 18) of the patients with obsessional traits seemed post-operatively to be less ruminatively preoccupied with their pain. In the majority, obsessional personal habits persisted unchanged.

In six patients paranoid reactions were present. In three they were less marked post-operativelyperhaps through an elevation of mood (Cases 7, 13, and 18) - and in three they became more predominant-perhaps through a reduction of self-control (Cases 10, 12, and 25).

When diffuse or disseminated organic cerebral damage was present pre-operatively it may be presumed that it contributed to the final total organic state. Such organic changes do not necessarily preclude a successful operation (Cases 7 and 10). Three other cases in which cerebral damage was present and which were classified as unimproved or worse (Cases 18, 21, and 24) probably obtained some relief from suffering.

Sex, Age, Duration of Symptoms, and Social Milieu

There were few consistent differences between the results obtained with men and women. At final follow-up the women averaged 29.4 on the combined social rating scale and the men averaged 31.0 points.

Older patients did rather better than younger ones. Twelve patients aged 56 and over averaged
10.3 points of improvement, 13 patients aged 54 and younger averaged only 6.8 points. This may well reflect the fact that less is expected of those who have reached retiring age.

As might have been expected, the longer the duration of the illness the less good was the result. Twelve patients whose illnesses had lasted six years or more averaged 6.8 points of improvement, 13 patients with durations of five years and less averaged $10 \cdot 0$.

Almost all studies of the effects of leucotomy in psychiatric disorders stress the importance of the social environment to which the patient has to return. Where this is favourable, the prognosis is much improved. A similar influence appears in the present series, but as might be expected this variable played a relatively less important role. It is, however, important to consider which aspect of the social milieu bears the main burden of the patient's postoperative condition. If we look at recovery in terms of fitness to resume pre-operative employment, we find that of the 25 cases under review, five were over 64 years old and had retired. However, of these, two were able to resume a fully responsible family role, and one improved to the extent that with support from his wife he was able to enjoy his re- $\frac{}{\mathbb{C}}$ tirement. Of the 20 patients of employable age, eight were housekeeping, and of these five resumed their home duties, though two functioned at a reduced capacity. Of the 12 patients gainfully employed pre-operatively, five returned to work (four at their original level and one at a reduced capacity). Thus 13 patients were able to return to their previous level of activity, though four of them functioned at a lower level. Of the 12 who failed to do so, four remained at home relatively incapacitated and the condition of eight was such that they were eventually permanently looked after in institutions. Only in one case was this failure due to lack of reasonable cooperation on the part of the family. Of the 17 patients who continued to live at home, 10 (Cases 1 , $2,5,6,8,15,18,19,22,23)$ were able postoperatively to resume a life of independence. The remaining seven patients were able to remain at home because of family support, without which they would have needed institutional care.

Only in one case (No. 18) did the patient's postoperative personality defects result in a break-up of the family. This patient suffered with severe spasmodic torticollis, and had inevitably messy eating habits. Some post-operative deterioration in his personal standards greatly distressed his hitherto united family. On the death, one year after his operation, of his wife, always the mainstay of the family, relations between him and his unmarried children deteriorated rapidly and they left home. 
He later went to live with his married daughter, where he remained a great trial and a disturbing influence in the home.

\section{Personality Changes}

Appreciable damage to frontal lobe tissue will inevitably produce personality changes of greater or lesser degree. The assessment of human values is bound to be subjective, but where the personality pre-operatively is not perfect there is no theoretical reason why these changes should not be an improvement. In at least six of our 25 patients it is not obvious that the changes were on balance unpleasant in character.

In the 16 patients treated with limited operations the personality changes were classified as negligible in two, as slight in six, and as definite in six. Only in two cases were they marked or severe. It is suggested below that in these two cases the damage to frontal tissue may have been greater than planned. In the nine patients treated by extensive operations the changes were classified as definite in two, marked in four, and severe in three. There is thus a close association between the extent of the lesion and the extent of the personality changes.

\section{Morbidity}

In addition to the changes of personality which are expected to occur after leucotomy due account must be taken of the operative risk of untoward complications. The present series is small. There were no operative deaths. One patient (Case 1) had a delayed haemorrhage which may have contributed to the excellent results obtained. Two patients (Cases 12 and 14) developed personality changes which were undoubtedly excessive for the modified operations planned. Three other patients developed epileptic attacks.

Meyer and Beck (1954) have shown that with standard leucotomies the amount of damage inflicted is often less than that intended; but we are not aware of any series of pathological investigations which demonstrate how often a modified leucotomy is more extensive than planned. Extrapolation from 25 patients is unjustified, but the present findings are not incompatible with those of other workers, and in particular with those reported by Pippard (1956) from a series of 240 rostral leucotomies. He reports an operative mortality of $1 \%$, an incidence of a further $1 \%$ for severe unexpected personality changes, and a figure of $5 \%$ for operative haemorrhages of little clinical significance. Pippard states that epilepsy occurs in $5 \%$ of cases but that it is exceptional for it to be of any consequence. Freeman in two extensive studies (1953a and $b$ ) concludes that the post-operative epilepsy rate depends largely on the extent of the operation and its nearness to the motor cortex.

\section{Discussion}

In the long-term treatment of cases of intractable pain by leucotomy the importance of the extent of the operation in determining the degree of relief obtained has previously been demonstrated in a larger series of cases by, amongst others, the Harvard workers (Bonner et al., 1953) and in France by Petit-Dutaillis et al. (1953). The observation that a mild pain is more readily relieved than a severe one is practically a truism. It needs emphasis, however, to offset the tendency to classify intractable pain as either real and severe or neurotic and imaginary. The third main finding that it is the type of psychiatric disturbance, rather than its presence or absence, which is important in determining the outcome of leucotomy for intractable pain has previously been relatively neglected and bears further discussion.

Leucotomy is infrequently called for in the treatment of intractable pain. In Jousse's 118 cases of painful traumatic paraplegia this operation was used only in one case. The result was excellent (Botterell et al., 1954). More recently FischerWilliams (1956) has reported on the treatment of 77 consecutive patients with complaints of intractable or obscure pain. None of her cases required leucotomy and she concludes that this operation is rarely necessary; however, in several of the cases a variety of other treatments were ineffective. Leucotomy is essentially a treatment for suffering rather than for pain, and it is important to remember that frontal lobe operations relieve only some of the psychological reactions which contribute to suffering. It is important also to remember that other methods of changing the attitude to pain, e.g., electroconvulsive therapy or psychotherapy, may at times be equally effective (Von Hagen, 1957).

It is often impossible to say why one patient with a herpetic root infection develops post-herpetic neuralgia, while another does not. While in most cases it is no doubt a matter of a difference in the severity of the sensations, there will also be other differences related to the vulnerability of the personality.

There is now abundant evidence that leucotomy does not affect the perception of pain and that the immediate autonomic and behaviour disturbances aroused by a novel painful stimulus are, if anything, greater after leucotomy damage. On the other hand, after leucotomy these disturbances are less prolonged and less readily aroused by a threat that the pain experience will be repeated (Elithorn et al., 1955). The chief action of leucotomy, therefore, is to 
modify behavioural disturbances which are temporally separated from the provocative insult.

Frequent severe pains produce a common pattern of insomnia, anorexia, weight loss, and depression; but where the pain itself is less severe, the psychiatric picture is more variable, reflects the predominant psychological organization of the patient and determines the character and degree of the disability. Thus the patient who complains of pain may be incapacitated, not directly by the pain, but because he has become depressed, because he is ruminatively preoccupied by his sensations, because he anxiously fears a recurrence of the pain, has anxieties about the significance of the underlying pathology, or fears that he will become incapacitated. He may, if the reaction is an hysterical one, be incapacitated not so much by the anxiety or depression as by his belief in his incapacity. This belief may unconsciously determine symptoms and incapacity greater than physiological limitations determined by the physical lesions.

Leucotomy has two main actions. Like electroconvulsive therapy it has a shock effect which breaks up established moods, particularly of the depressive type. Unlike electroconvulsive therapy it produces a focal and persisting neurological defect which causes changes in the psychological disposition of the patient. The change most frequently reported is a reduction in the tendency to become anxious. It has been suggested in relation to our experimental results that this can be attributed to damage to the mechanisms underlying the formation of anticipatory sets. In effect the perception of a stimulus still gives rise to the concept of a future event but there is a failure to elaborate an emotional state appropriate to this concept. In patients with intractable pain each attack of pain normally carries its own immediate affective connotation and also acts as a warning signal leading to a heightened expectation of further attacks. It is the affective change associated with the awareness of these secondary consequences of a painful stimulus which is reduced by leucotomy.

Normally the affective state aroused by a painful stimulus or the threat of a painful stimulus is an excitatory or anxious one, but, as Russell Davis (1952) has pointed out, the repetition of an excitatory stimulus may lead eventually by a process of habituation to an inhibitory or depressive state. Hence by damaging these mechanisms leucotomy would reduce the ability of the patient to elaborate moods of both anxiety and depression.

The typical post-leucotomy syndrome in cases of intractable pain is thus one in which the patient still makes complaints of severe pain but shows at the same time an affect inappropriately cheerful.
Such a syndrome in the absence of an operation and of an objectively demonstrable cause for pain would readily give rise to a diagnosis of hysteria. It might not be meaningless, therefore, to suggest that while leucotomy lessens the individual's propensity to reactions which are anxious or depressive it increases the tendency to reaction of an hysterical type. Such a formulation is not at variance with the observation that our hysterical patients improved. They were, if anything, more hysterical. Their complaints of pain were with one exception unchanged but carried less conviction. One patient (Case 13), post-operatively " just the same", had convinced his wife also that he was no better. On further enquiry, however, she admitted that he now smiled more frequently and never wept. The depth of this patient's hysterical reaction is suggested by the fact that he felt too weak to stir his own tea, and got his wife to do it for him.

The suggestion that frontal lobe damage impairs the ability to elaborate the affect appropriate to the concepts present in consciousness, combined with the fact that in anxiety states and reactive depressions this affective formulation is excessive, would explain the observation reported more than once in the literature (Freeman and Watts, 1950; Hardy, Wolff, and Goodell, 1952) that personality deterioration is less marked in patients operated on for psychiatric reasons than in psychiatrically normal patients leucotomized for intractable pain. In the first case the operation would damage mechanisms which were overactive; in the second they would pre-? operatively be adequate. In severe hysterics the pre-operative personality suffers already from the primitive nature of the mechanisms underlying emotional elaboration. Hence, although postoperatively the hysteric is more selfish, egocentric, and emotionally labile, the relative may notice little difference. The wife of one patient (Case 9) reported that he was as selfish and as chronic an invalid as ever and that his personality was unchanged. The patient said that he no longer got depressedotherwise there was no change. More detailed enquiries established that the patient was more and not less selfish than before the operation but had lost some of his ability to implement his policies when opposition was aroused.

In considering cases of intractable pain for leucotomy, therefore, it must be remembered that the pain will not be relieved and that normal people cannot by leucotomy be made inattentive to severe pain unless the operation produces a very definite dementia. Hence the main indication in cases of intractable pain is an excessive psychological reaction of the anxious, depressive, or ruminative type. The more likely it is that the patient is suffering from 
severe physical pain, then the less likely it is that leucotomy will help him. Where there is severe organic pain some personality change is essential to the success of the operation. Where a severe hysterical reaction is not secondary to anxiety or depression, the chances of a good result are diminished. Since the risks of either excessive personality change, of post-operative epilepsy, or of operative death amount to about $7 \%$, it is clear that operation is only justified if a direct attack on the pain is impossible and if no other treatment of the psychiatric reaction is practicable.

The treatment of intractable pain, i.e., pain for which the physical cause is beyond treatment, constitutes a problem of the greatest importance to medicine. It is clear that damaging operations on the frontal lobes provide no satisfactory answer. They have some part to play at the present time, but only because of our incapacity to do anything better. These operations do not shield the patient against the recurrence of his pain, but, at the cost of personality changes, interfere with some of the psychological concomitants of physical suffering.

\section{Summary}

Twenty-five patients treated for intractable pain by leucotomy-type operations have been followed up for between 18 and 78 months. The results of the operations were assessed by the patient, by the relative most concerned, clinically, and with a rating scale designed to evaluate social adjustment.

Clinical evaluation suggested that 17 of the 25 patients had been clearly helped by the operation. Twenty $(80 \%)$ showed an overall gain on the social rating. However, only eight $(35 \%)$ of 23 patients and eight $(38 \%)$ of 21 relatives thought that the operation had been worth while. (In a larger series of leucotomies undertaken primarily for psychiatric reasons, $75 \%$ of 80 patients and $89 \%$ of 72 relatives thought the operation had been helpful.) It is concluded that the tendency for patients and relatives to be dissatisfied with a leucotomy for pain is related to the observation that although most patients admitted to some improvement in their symptoms, only five thought that their pains were less intense.

With regard to the type of operation used, the patients, the relatives, and the clinical assessment all reported more favourable results with " extensive" operations than with "limited" ones. In contrast, patients who had "limited" operations tended to show bigger gains on the social rating scales. This discrepancy is related to the fact that while more extensive operations tend to produce greater relief from suffering, they are also more likely to lead to socially crippling defects of personality.
The results of the present study support the following conclusions:

Operations on the frontal lobes-unless they are very extensive-do not impair the subject's ability to perceive and react appropriately to a painful stimulus, but produce relief by impairing his ability to elaborate a persisting attitude or mood.

The probability that leucotomy will provide relief for a patient suffering from intractable pain depends first on the severity of the painful sensations and secondly on the nature of the psychological reaction. Where the pain is not severe and the psychological reaction is largely a depressive or anxious preoccupation with symptoms, the prospects of some degree of relief are high. If pain is severe and frequent, little permanent relief is to be expected. Where hysterical tendencies are present, these may be increased, but since the anxiety which provokes the hysterical symptoms may be reduced, the total change is often a gain in social adaptation.

Operations on the frontal lobe are an unsatisfactory treatment for intractable pain, but if pain cannot be alleviated by other means then in carefully selected cases leucotomy-type operations may produce both relief from suffering and an improved social adjustment.

\section{REFERENCES}

Bonner, F., Cobb, S., Sweet, W. H., and White, J. C. (1953). Res. Publ. Ass. nerv. ment. Dis., 3i, 392 .

Botterell, E. H., Callaghan, J. C., and Jousse, A. T. (1954). Proc. roy. Soc. Med., 47, 281 .

Chapman, W. P., Rose, A. S., and Solomon, H. C. (1950). Amer. J. Psychiat., 107, 221.

Davis, D. R. (1952). Brit. J. med. Psychol., 25, 104.

Dynes, J. B., and Poppen, J. L. (1949). J. Amer. med. Ass., 140, 15.

Elithorn, A., Piercy, M. F., and Crosskey, M. A. (1955). J. Neurol. Neurosurg. Psychiat., 18, 34.

Fischer-Williams, M. (1956). Brit. med. J., 2, 739.

Freeman, W. (1953a). J. Amer. med Ass., 152, 487

- (1953b). Neurology, 3, 479.

, and Watts, J. W. (1950). Psychosurgery in the Treatment of Mental Disorders and Intractable Pain, 2nd ed. Thomas, Springfield (Illinois).

Grantham, E. G. (1950). Sth. Surg., 16, 181.

Hamlin, H., Delgado, J. M. R., Chapman, W. P., and Rosvold, H. E. (1953). Sth int. neurol. Congr., Lisbon, Vol. 4, p. 406.

Hardy, J. D., Wolff, H. G., and Goodell, H. (1952). Pain Sensations and Reactions. Williams \& Wilkins, Baltimore.

Jackson, H. (1954). J. ment. Sci.. 100, 62 .

King, H. E., Clausen, J., and Scarff, J. E. (1950). J. nerv. ment. Dis. 112, 93.

Le Beau, J., Choppy, M., Gaches, J., and Rosier, M. (1954). Psychochirurgie et fonctions mentales. Masson, Paris.

, and Gaches, J. (1949). Sem. Hôp. Paris, 25, 222.

McKissock, W. (1953). Practitioner, 171, 34.

Meyer, A., and Beck. E. (1954). Prefrontal Leucotomy and Related Operations. Oliver \& Boyd, Edinburgh.

Partridge, M. (1950). Prefrontal Leucotomy. Blackwell, Oxford.

Petit-Dutaillis, D., Messimy, R., and Berges, L. (1953). Sem. Hôp. Paris, 29, 3893 .

Pippard, J. (1955). J. ment. Sci., 101, 756.

(1956). Brit. med.J., 1, 1402

Sargant, W. (1953). Brit. med. J., 2, 800.

Scarff, J. E. (1950). J. Neurosurg., 7, 330

Schilder, P., and Stengel, E. (1931). Arch. Neurol. Psychiat. (Chicago), 25, 598.

Smolik, E. A. (1950). Dis. nerv. Syst., 11, 327.

Turnbull, F. (1954). Proc. roy. Soc. Med, 47, 155.

Von Hagen, K. O. (1957). J. Amer. med. Ass., 165, 773. 